\title{
Peningkatan Pengetahuan Ibu-Ibu Tentang Bahaya Zat Warna Rhodamin B Terhadap Kesehatan Anak Usia Sekolah di Kelurahan Sidomulyo Timur
}

\author{
Yelfira Sari ${ }^{1 *}$, Asyti Febliza², Sumandar ${ }^{3}$ \\ ${ }^{1,2}$ Universitas Islam Riau, Indonesia \\ ${ }^{3}$ STIKES Al-Insyirah Pekanbaru \\ yelfirasari@edu.uir.ac.id
}

\begin{abstract}
ABSTRAK
Anak yang sehat, kuat, cerdas, serta berkualitas merupakan penentu penggerak pembangunan di masa yang akan datang. Oleh karena itu, perlu perhatian khusus terhadap anak-anak tersebut terutama dalam pemenuhan gizi yang seimbang serta keamanan makanan yang mereka konsumsi. Asupan gizi dapat berasal dari makanan yang disediakan di rumah oleh orang tua, makanan kemasan yang diperdagangkan secara komersial, makanan cepat saji, dan makanan jajanan yang di jual di lingkungan sekolah. Jajanan yang biasanya dikonsumsi oleh anak usia sekolah merupakan masalah yang harus diperhatikan baik oleh orang tua maupun oleh guru-guru. Jajanan ini umumnya ditambahkan Bahan Tambahan Pangan (BTP) dan salah satunya adalah zat warna. Contohnya adalah penambahan Rhodamin B. Rhodamin B merupakan zat warna merah yang banyak digunakan dalam industri, khususnya industri tekstil. Jika anak usia sekolah mengkonsumsi makanan atau minuman yang mengandung zat berbahaya ini, maka lama kelamaan akan mengendap pada jaringan hati dan lemak serta dapat menurunkan kinerja otak sehingga anak-anak akan menjadi malas dalam belajar.
\end{abstract}

Kata Kunci: Bahan Tambahan Pangan, Jajanan, Rhodamin B

Received: September, 16, 2019

Revised: December 12, 2019

Accepted: February 11, 2020

This is an open-acces article distributed under the terms of the Creative Commons Attribution-ShareAlike 4.0 International License.

\section{PENDAHULUAN}

Agar stamina anak sekolah tetap bugar selama mengikuti proses pembelajaran, maka diharuskan untuk sarapan pagi sebelum berangkat ke sekolah. Energi yang dibutuhkan dalam sarapan tersebut dianjurkan berkisar sepertiga dari kebutuhan energi harian. Namun, jika kebutuhan energi yang diperoleh dari sarapan belum mencukupi, maka perlu makanan selingan. Makanan selingan ini berfungsi agar kadar gula darah anak sekolah tetap terjaga sehingga konsentrasi dalam menerima pelajaran di sekolah tidak terganggu. Makanan selingan dapat diperoleh dari bekal yang disiapkan oleh orang tua maupun dari jajanan yang terdapat di sekolah (BPOM 2013), (Dyna, Putri, and Indrawati 2018). 
Terdapat beragam jenis makanan jajanan yang dijual di kantin sekolah maupun pedagang-pedang di sekitar sekolah. Makanan jajanan tersebut dibuat sangat menarik baik dari segi warna, bentuk, maupun rasa (Ayuniah, Indriani, and Rangga 2015), (Sultan et al. n.d.), (Pertiwi et al. n.d.). Terdapat empat jenis makanan jajanan anak sekolah, yaitu makanan utama atau dikenal juga dengan istilah jajajan berat, camilan/snack, minuman, serta jajanan buah. Namun, sebagian besar jajanan anak sekolah kurang memenuhi standar gizi, tidak higienis, serta beresiko terhadap cemaran biologis maupun kimiawi (BPOM 2013).

Umumnya untuk mendapatkan jajanan dengan warna yang menarik serta rasa yang menggugah selera dengan harga yang terjangkau bagi para siswa, pedagang umumnya menambahkan suatu zat yang disebut dengan BTP (Bahah Tambahan Pangan) (Andayani 2013). BTP ada yang diizinkan penggunaannya oleh pemerintah serta ada yang dilarang penggunaannya. Salah satu yang dilarang penggunaannya adalah zat warna Rodhamin B. Zat warna ini biasanya digunakan pada industri dan kertas serta memiliki sifat karsinogen (Abd, Ahmed, and Zhu 2017), (Liu et al. 2013). Jika anak usia sekolah mengkonsumsi makanan atau minuman yang mengandung zat berbahaya ini, maka lama kelamaan akan mengendap pada jaringan hati dan lemak serta dapat menurunkan kinerja otak sehingga anak-anak akan menjadi malas dalam belajar .

\section{METODE}

Kegiatan Pengabdian kepada Masyarakat ini dilaksanakan di RT 009 RW 006 Kelurahan Sidomulyo Timur Kecamatan Marpoyan Damai Kota Pekanbaru-Riau. Transfer IPTEKS yang akan dilakukan oleh Tim Pelaksana kegiatan Pengabdian kepada Masyarakat $(\mathrm{PkM})$ dilakukan pada tiap tahapan dengan menggunakan prinsip bahwa setiap informasi dan inovasi yang diterima oleh Mitra sebaiknya melalui proses, mendengar, mengetahui, mencoba, menerima, meyakini, dan melaksanakan serta mengevaluasi. Agar setiap proses berlangsung dengan baik, maka penyampaian inovasi kepada Mitra dilakukan dengan tahapan penjelasan, diskusi, praktek serta dilakukan pembimbingan.

Penerapan IPTEKS yang dilakukan adalah dengan melakukan pemaparan kepada ibu-ibu peserta pengabdian tentang bahaya mengkonsumsi makanan dan minuman yang mengandung zat warna Rhodamin B melalui presentasi Power Point (PPT).

\section{HASIL DAN PEMBAHASAN}

Kegiatan Pengabdian kepada Masyarakat yang telah dilakukan di RT 09 RW 06 Kelurahan Sidomulyo Timur Kecamatan Marpoyan Damai Kota Pekanbaru-Riau dihadiri oleh 15 orang peserta yang terdiri atas ibu-ibu PKK setempat. Pelaksanaan kegiatan dilakukan beberapa tahap, yaitu permohonan izin untuk melakukan kegiatan pengabdian dari ketua PKK serta penyuluhan/sosialisasi tentang bahaya zat warna Rhodamin B terhadap kesehatan Sosilisasi dilakukan dengan media Power Point (PPT) menggunakan laptop dan proyektor.

Penyampaian materi dimulai dengan membahas tentang kebiasaan jajan bagi anak usia sekolah serta jajanan yang tidak sehat. Jajanan yang tidak sehat dapat berasal dari kekurang-higienis-an para pedagang dalam mengolah barang dagangan mereka maupun dengan adanya penambahan zat yang tidak semestinya ke dalam makanan. Salah satu zat yang sering ditambahkan untuk menarik minat para siswa adalah zat warna. Salah satunya 
berupa zat warna merah Rhodamin B. Zat warna ini sering disalahgunakan oleh pedagang yang tidak bertanggung jawab dengan menambahkannya ke dalam makanan ataupun minuman yang mereka jual. Padahal, penggunaan semestinya Rhodamin B adalah sebagai pewarna tekstil dan kertas. Selanjutnya juga disampaikan tentang bahaya zat warna Rhodamin B terhadap kesehatan, terutama bagi anak-anak serta cara membedakan makanan yang ditambahkan zat warna makanan ataupun zat warna tekstil.

Berdasarkan kegiatan pengabdian yang telah dilakukan dapat diketahui bahwa pemahaman ibu-ibu tentang pemilihan jajanan sehat telah meningkat. Hal ini terbukti dari antusiasme ibu-ibu tersebut dalam melakukan proses tanya jawab. Dengan adanya kegiatan Pengabdian kepada Masyarakat ini, ibu-ibu tersebut menjadi mengenal zat warna Rhodamin B serta bahaya yang dapat ditimbulkannya akibat konsumsi zat warna tersebut.

\section{KESIMPULAN}

Berdasarkan kegiatan yang telah dilakukan, dapat disimpulkan bahwa kegiatan Pengabdian kepada Masyarakat ini telah membawa wawasan baru bagi ibu-ibu di komplek perumahan Beringin Indah tentang pentingnya memilih jajanan sehat bagi anak-anak mereka serta bahaya penggunaan zat warna tekstil dalam makanan terutama bahaya Rhodamin B.

\section{UCAPAN TERIMA KASIH}

Penulis mengucapkan terima kasih kepada LPPM UIR atas dukungan dana yang diberikan dalam kegiatan Pengabdian kepada Masyarakat serta dalam proses publikasi dari hasil kegiatan ini.

\section{DAFTAR PUSTAKA}

Abd, Almojtaba, Alkhalig Ahmed, and Xia Shi Zhu. 2017. "Determination of Rhodamine B Pigment in Food Samples by Ionic Liquid Coated Magnetic Core / Shell Fe 3 O 4 (a) SiO 2 Nanoparticles Coupled with Fluorescence Spectrophotometry." 5(1): 1-7.

Andayani, Dahlia. 2013. "Analisis Zat Pewarna Rhodamin B Pada Gula Kapas Merah Yang Dijual Di Kota Mataram Tahun 2013.” 902: 2-5.

Ayuniah, Qurrotun, Yaktiworo Indriani, and Kordiyana K Rangga. 2015. "Ketersediaan Dan Perilaku Konsumsi Makanan Jajanan Olahan Siswa Sekolah Dasar Di Bandar Lampung." JIIA 3(4): 409-18.

BPOM. 2013. "Pedoman Pangan Jajanan Anak Sekolah Bagi Pencapaian Gizi Seimbang Bagi Orang Tua, Guru, Dan Pengelola Kantin."

Dyna, Fitri, Veni Dayu Putri, and Dwi Indrawati. 2018. "HUBUNGAN PERILAKU KOMSUMSI JAJANAN PADA PEDAGANG.” 3(3): 524-30.

Liu, Xiuying et al. 2013. "Spectrometric Determination of Rhodamine B in Chili Powder After Molecularly Imprinted Solid Phase Extraction.” 34(11): 3381-86.

Pertiwi, Dian et al. "ANALISIS KANDUNGAN ZAT PEWARNA SINTETIK RHODAMIN B DAN METHANYL YELLOW PADA JAJANAN ANAK DI SDN 
KOMPLEKS MANGKURA KOTA MAKASSAR ANALYSIS OF THE CONTENT OF DYE SYNTHETIC SUBSTANCES RHODAMINE B AND METHANYL

YELLOW IN THE SNACKS OF Hasil Monitoring Dan Verifikasi Profil Keamanan Pangan Jajanan Anak Sekolah ( PJAS ).” : 1-14.

Sultan, Pramutia et al. "ANALYSIS OF THE CONTENT OF BORAX ON MEATBALLS SNACK IN." : 1-11. 